\title{
Idaho National
}

Laboratory/Nuclear Power

Industry Strategic Plan for Light

Water Reactor Research and

Development

An Industry-Government

Partnership to Address Climate

Change and Energy Security

Electrolysis Plants Coupled to

Three Advanced Reactor Types

November 2007

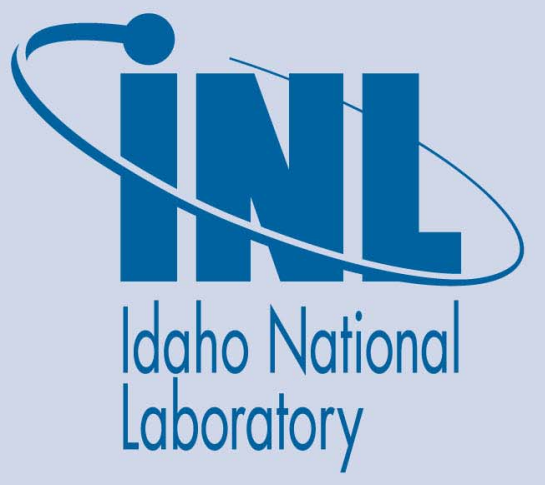

The INL is a U.S. Department of Energy National Laboratory operated by Battelle Energy Alliance 
INL/EXT-07-13543

\section{Idaho National Laboratory/Nuclear Power Industry Strategic Plan for Light Water Reactor Research and Development An Industry-Government Partnership to Address Climate Change and Energy Security}

November 2007

Idaho National Laboratory Idaho Falls, Idaho 83415

Prepared for the U.S. Department of Energy Office of Nuclear Energy Under DOE Idaho Operations Office

Contract DE-AC07-05ID14517 

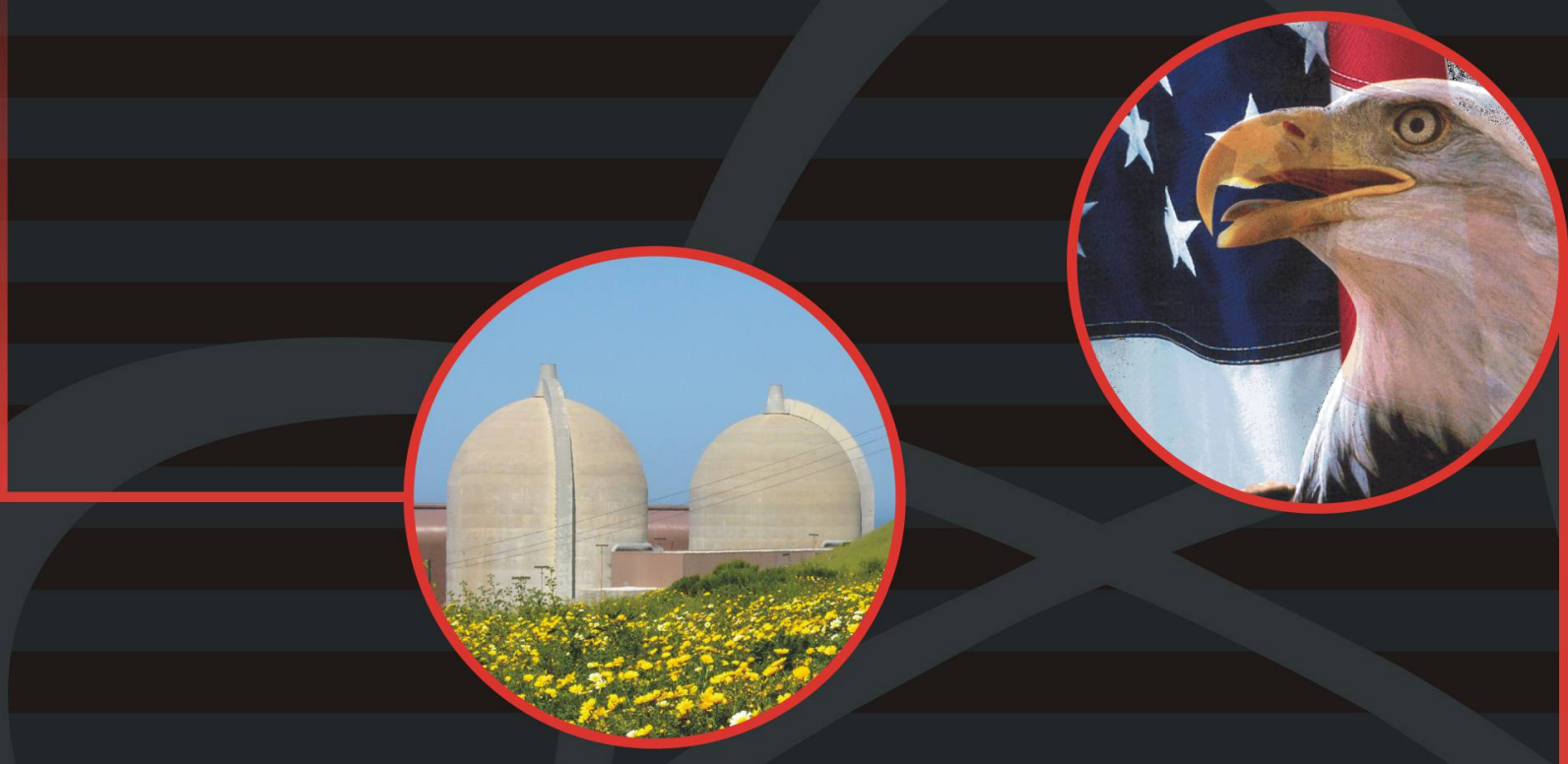

Idaho National Laboratory/Nuclear Power Industry

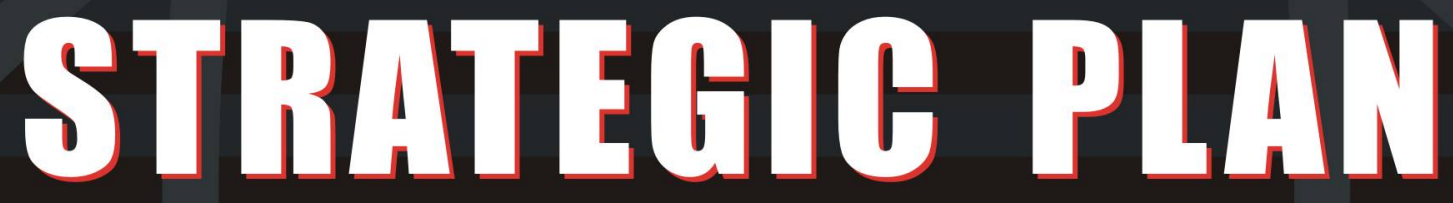
for Light Water Reactor Research and Development

An Industry-Government Partnership to Address Climate Change and Energy Security

November 2007

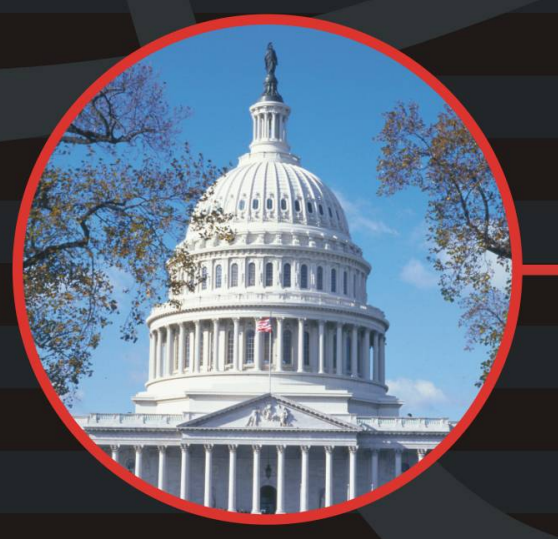





\section{Foreword}

The dual issues of energy security and climate change mitigation are driving a renewed debate over how to best provide safe, secure, reliable and environmentally responsible electricity to our nation. The combination of growing energy demand and aging electricity generation infrastructure suggests major new capacity additions will be required in the years ahead. Recent analysis by EPRI shows that all low emission electricity technologies will be required to satisfy anticipated goals for reduced $\mathrm{CO}_{2}$ emissions - renewable energy, nuclear energy, clean coal with $\mathrm{CO}_{2}$ capture and sequestration, and energy efficiency.

There is a growing consensus that large $\mathrm{CO}_{2}$ reductions cannot be achieved without a major contribution from nuclear energy. Nuclear energy plants produce no greenhouse gases. Further, U.S. nuclear plants have consistently maintained outstanding levels of nuclear safety, reliability, and operational performance over the last two decades. Today, nuclear production costs are the lowest among major U.S. generating options.

Due in large measure to the Department of Energy (DOE) NP-2010 Program and Congressional support for expanding nuclear energy, the nuclear industry has plans to construct about 30 new nuclear plants in the U.S. starting next decade. Similar growth is planned and underway around the world.

It is important to note that all of the currently operating nuclear plants in the U.S. and all the planned additions of nuclear plants in the foreseeable future employ Light Water Reactor (LWR) technology. Yet with the exception of the NP-2010 program (which is aimed largely at assisting industry demonstrate the new licensing process for new plants), very little Federal investment has been made in advancing LWR technology over the last decade. Most Federal investments in nuclear energy have been in non-LWR technologies that, while promising and deserving of support, do not directly address the challenges of energy security and climate change mitigation in the near term. Industry has thus carried the R\&D responsibility for LWR technology over these years, with short-term needs dominating the research agenda.

The growing realization that a renaissance in nuclear plant construction is looming large has caused both industry and government to rethink the nuclear energy research agenda. Starting early this year, industry, DOE, and NRC have begun discussing the challenges ahead and our ability to meet them in ways that maintain high standards of safety and performance for both the existing fleet and the new fleet. A consensus has emerged that we are probably adequately prepared for modest growth in nuclear energy, but poorly prepared for large scale expansion.

Further, as the obstacles to very large buildrates of new nuclear plants were examined and understood, a renewed focus emerged on the importance of our current fleet. The limitations to new plant construction financing, infrastructure support, licensing, aging workforce, as well as a number of technical issues, all argued for taking a hard look at what it would take to enable further life extension of the existing fleet, even beyond the current license renewals from 40 to 60 years. Some of the likely solutions to extended life of the current fleet will also apply to the needs of the new fleet, particularly when one considers the challenges associated with very large new plant build rates. 
From these considerations emerged a vision, two "stretch" goals," and this Strategic Plan for LWRs:

Vision: Nuclear energy will reduce U.S. and global carbon emissions and enhance the nation's energy security. Greater U.S. reliance on nuclear energy will improve its international engagement and leadership on nuclear safety and security issues.

\section{Stretch Goals:}

1. Life extension of the current fleet beyond 60 years (e.g., what would it take to extend all lives to $\sim 80$ years?); and

2. Strong, sustained expansion of ALWRs throughout this century (e.g., what would it take to proceed uninterrupted from first new plant deployments in $\sim 2015$ to sustained build-rates approaching 10+/year?).

The Strategic Plan that follows this Foreword expands these two stretch goals into two specific goals for current plants and four specific goals for new plants. The Strategic Plan then presents ten specific R\&D objectives that generally benefit both current and new plants. The document then presents a high level "Path Forward" for how industry and government should work together to implement this Strategic Plan.

Industry recognizes that LWR technology is mature and that industry should carry a large burden in maintaining this technology as it is applied in the commercial sector.
However, this plan demonstrates that the magnitude of the challenges facing this nation, in energy security and climate change response, require the active engagement and leadership of the Federal Government in a number of strategic areas where industry cannot succeed on its own. A public-private partnership is needed to address many of these challenges, under which industry and government would share the costs and responsibilities.

International collaboration is an essential part of this plan. Working with other nations on the peaceful use of nuclear energy brings with it renewed respect for U.S. technology, regulations, and institutions. $R \& D$ collaboration is a pathway to improved nuclear safety and enhanced nonproliferation globally.

This Strategic Plan is intended to establish a framework that will allow the DOE and the nuclear energy industry to jointly plan the nuclear energy R\&D agenda and jointly execute those elements of the plan that are appropriate for joint effort. By working together under this framework, the nuclear industry will maintain a joint commitment with the Federal Government to the safe and economic use of nuclear power and to the National Energy Policy's goal of expanding its use in the United States. The undersigned believe that a public-private partnership approach is the most efficient and effective way to develop and transfer new technologies to the marketplace to achieve this goal.

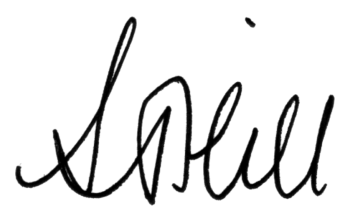

David J. Hill, Ph.D.

Laboratory Deputy Director for Science and Technology Idaho National Laboratory

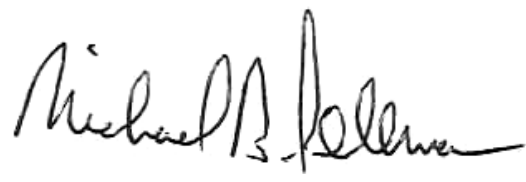

Michael B. Sellman

President \& CEO,

Nuclear Management Co.

Chairman, Idaho National Laboratory

Utility Advisory Board

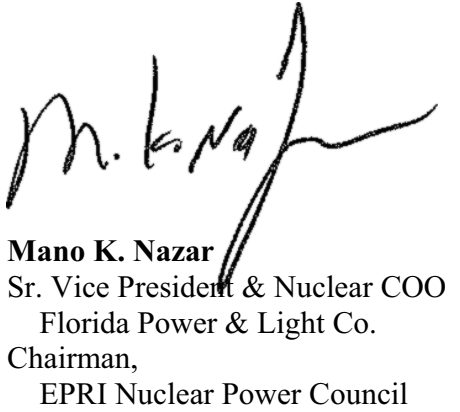




\section{Table of Contents}

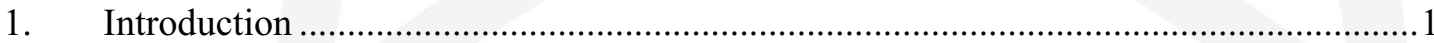

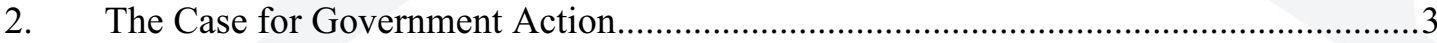

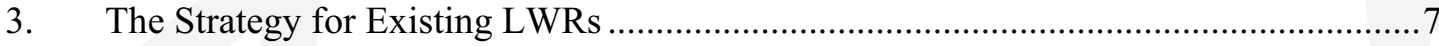

4. The Strategy for Advanced LWRs ........................................................................

5. Research and Development Scope and Objectives.................................................... 11

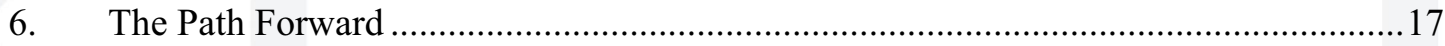

Collaborative Program Planning and Joint Funding....................................................17

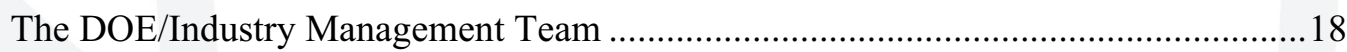

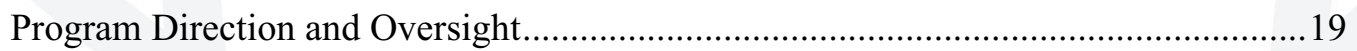

Appendix

A: Similarities with Goals of Other DOE Energy Programs ........................................21 



\section{Introduction}

With a growing awareness of the importance of mitigating climate change and addressing the need for greater energy security, the world is once again looking to nuclear energy. The National Energy Policy ${ }^{\mathrm{a}}$ called for the expansion of nuclear energy in the U.S. as a major component of national energy policy. This call led to a successful Nuclear Power 2010 (NP2010) program that helped stimulate the license renewals for the current fleet of light water reactors (LWRs) and moved the U.S. toward ordering new advanced LWRs (ALWRs) - the first in three decades. President Bush has also called for the U.S. and other nations to set a long-term goal for reducing greenhouse gases and to establish a new framework on greenhouse gas emissions with mid-term targets by the time the Kyoto Protocol expires in 2012.

Nuclear energy currently enjoys growing bipartisan support and is viewed as playing a larger role in the nation's energy future. However, it is possible that expectations for nuclear energy could exceed the industry's capacity to build new plants. The vision for nuclear energy must therefore rise to meet the challenge of becoming one of the major contributors to both reducing U.S. and global carbon emissions in the decades ahead and enhancing the nation's energy

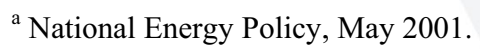

${ }^{\mathrm{b}}$ President Bush speech, May 31, 2007.
}

security. Greater U.S. reliance on nuclear energy will improve its international engagement and leadership on nuclear safety and security issues.

Nuclear energy has become a major source of safe, clean, economical, and reliable energy. For 30 years, nuclear power plants have generated $20 \%$ of the nation's electricity without emitting air pollutants or greenhouse gases; more U.S. electricity than any other source, except coal. In fact, nuclear energy provides the largest share (73\%) of non-emitting electricity generation in the U.S. today and appears positioned to displace more carbon emissions and serve a vital role in climate change initiatives.

Meeting the challenge of reducing carbon emissions while expanding the energy supply requires the development and deployment of non-emitting sources on an unprecedented scale. Today, through concerted actions of the world community, a number of initiatives are under way to address climate change. All are predicated on the stabilization and reduction of carbon in the atmosphere, to varying degrees, through a variety of technology and policy

Vision: Nuclear energy will reduce U.S. and global carbon emissions and enhance the nation's energy security. Greater U.S. reliance on nuclear energy will improve its international engagement and leadership on nuclear safety and security issues. 
options. The Electric Power Research Institute (EPRI) has recently studied a spectrum of options and created a balanced view on the potential contributions of all options to reduce U.S. carbon emissions (see Figure below). ${ }^{\mathrm{c}}$ They concluded that all options must be promoted; and yet, all options face challenges that must be overcome through research and development (R\&D) and policy initiatives.

This strategic plan examines the $R \& D$ needed in order for nuclear energy to expand dramatically_rising to a $25 \%$ share of electricity generation in 2030, and about
$40 \%$ by mid-century. The barriers to this growth are both technical and institutional. Although the R\&D strategy focuses on the actions needed to address the technical challenges, the institutional issues noted in the strategy must also be addressed.
This strategic plan examines the R\&D needed for nuclear energy to expand dramatically —rising to a $25 \%$ share of electricity generation in 2030, and about $40 \%$ by mid-century.

Technical Potential of $\mathrm{CO}_{2}$ Reductions for each Technology Option $\odot 2007$ EPRI

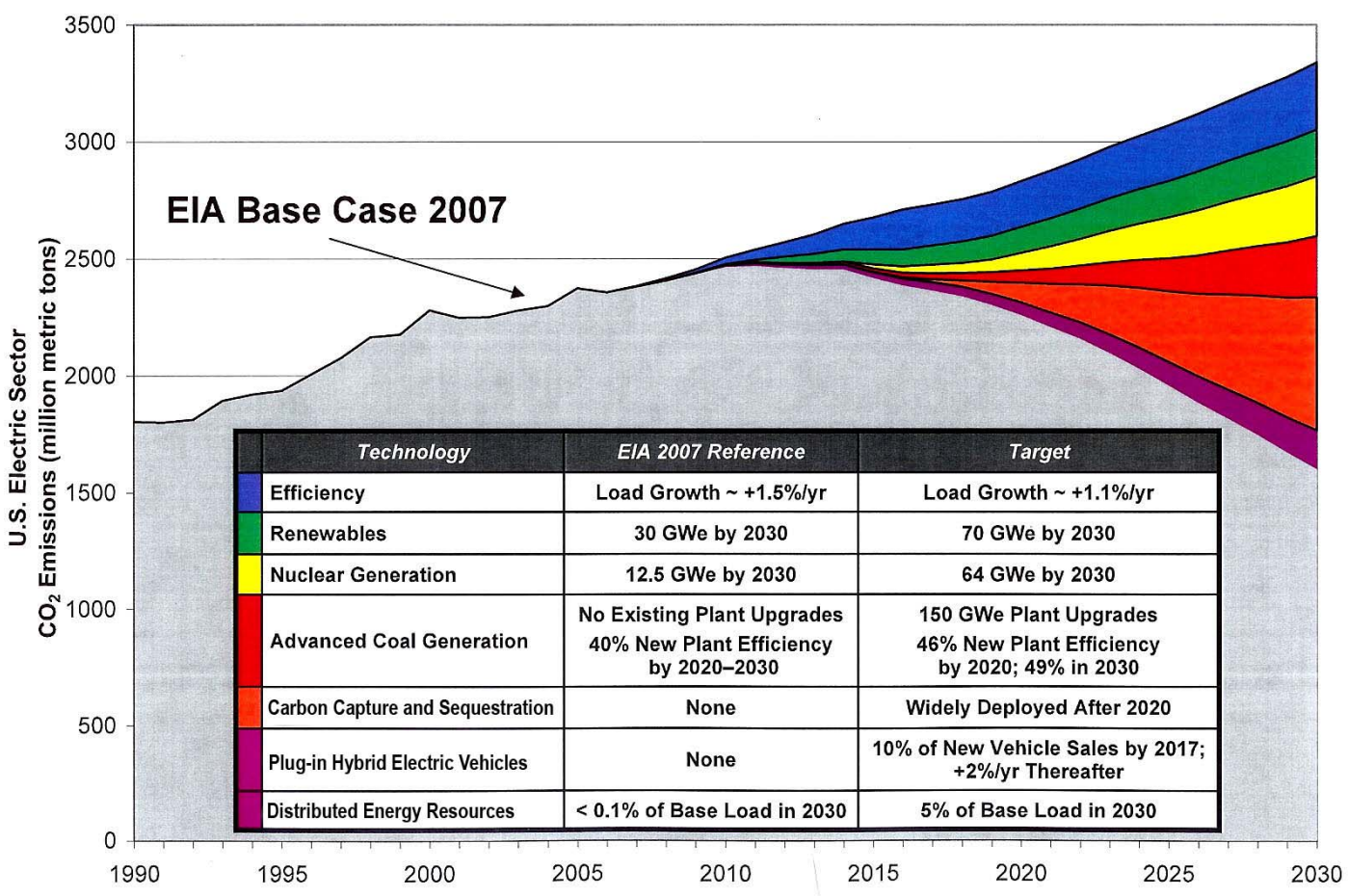

${ }^{\mathrm{c}}$ EPRI, The Power to Reduce CO2 Emissions, Aug. 2007. 


\section{The Case for

Advancing toward this more aggressive vision requires the partnership of industry and government. Together, they can overcome the barriers to large-scale deployment and deliver highly reliable plants with very long lifetimes, allowing both existing and new plants to flourish for many years.

This strategy supports the drive for nuclear power growth by focusing on LWRs, which stand out in technical maturity, experience, reliability, and industry acceptance. LWR technology represents over $80 \%$ of all the world's commercial reactors and comprises $100 \%$ of the U.S. fleet. It is the only technology being considered for commercial deployment in the U.S. today. Nations without nuclear energy programs and nations with non-LWR nuclear reactor technology foundations (such as Great Britain) are transitioning to greater reliance on LWRs for their future nuclear energy needs.

Other advanced reactor technologies, such as high-temperature gas-cooled reactors (HTGRs) and liquid metal cooled reactors (LMRs), which are being studied under the U.S. Department of Energy (DOE) GEN IV program, have potential and deserve investment in research, development, and demonstration (RD\&D). These designs will eventually prove advantageous over LWR technology in certain applications (e.g., HTGRs for process heat and hydrogen generation and LMRs for breeding nuclear fuel and recycling spent LWR fuel). HTGRs and LMRs are thus important areas for research because of the significant contributions they will make in future decades to augment the LWR technology nuclear energy backbone. Still, they are not alternatives to LWRs and must overcome large $\mathrm{RD} \& \mathrm{D}$ challenges before they can become cost-competitive.

In contrast, LWRs are essential to meeting the basic energy needs of the nation today by generating vast quantities of electricity safely, reliably, and economically. In turn, they will help fuel the U.S. economy and provide an acceptable quality of life for its citizens. LWRs are and will remain the workhorse for nuclear power generation for much of the $21^{\text {st }}$ Century. Further, future policies to reduce $\mathrm{CO}_{2}$ and other emissions from fossil fuels will inevitably drive an increased reliance on nuclear electricity, which, for the foreseeable future, will come from LWRs.

With the exception of the recent NP-2010 program, the U.S. Government has invested very little in LWR technology over the past decade. The NP-2010 program, however, is aimed at demonstrating an unproven licensing process and at facilitating "first mover" new nuclear projects, ${ }^{\mathrm{d}}$ not at

\footnotetext{
${ }^{\mathrm{d}}$ The Future of Nuclear Power, MIT 2003 (recommendations 1 and 2).
} 
addressing LWR technology development needs beyond the advancements made from previous R\&D and operational experience. Industry has stepped up to the challenge and largely sustained LWR technology needs on its own, with minimal Federal assistance. This situation has created unintended consequences, such as a significant disconnect between government and industry in nuclear energy strategy and planning.

This plan presents a path forward to better align industry and government R\&D priorities on LWR needs, within a more balanced and integrated strategy. Prior attempts to achieve this improved alignment include the 2004 version of this Plan ${ }^{\mathrm{e}}$ and the 2006 EPRI-INL Strategic Plan. ${ }^{f}$ A recent report by the National Academy of Sciences ${ }^{\mathrm{g}}$ identified this LWR R\&D gap in the federal energy R\&D portfolio and urged that it be closed.

This plan assumes that NP-2010 will be successful in demonstrating the untested licensing process for new ALWRs in the U.S., completing the designs of two innovative ALWRs, and facilitating near term deployment of the first six ALWRs. It also assumes that energy policy makers will mandate or incentivize, in some manner, increased reliance on low carbon generation in the coming years.

An EPRI study (Figure, Page 2, Reference c) concluded that significant reductions could be made if all advanced technologies were pursued and successful in making their contribution to the goal. $\mathrm{CO}_{2}$ stabilization at 1990 levels was possible (and affordable) if renewable energy (primarily wind power), nuclear energy, advanced coal with $\mathrm{CO}_{2}$ capture and sequestration, and energy

\footnotetext{
${ }^{\mathrm{e}}$ U.S. DOE / Nuclear Power Industry Strategic Plan for LWR Research and Development, Feb. 2004.

${ }^{\mathrm{f}}$ EPRI-INL Nuclear Energy Development Agenda: A Consensus Strategy for U.S. Government and Industry, Jan. 2006.

${ }^{\mathrm{g}}$ National Research Council of the National Academies, Review of DOE's Nuclear Energy Research and Development Program, Oct. 2007.
}

efficiency all deployed successfully in accordance with the aggressive growth plans advocated by each of these technology sectors. Using an economic model in broad use by climate change scientists, nuclear energy was shown to expand, even with modest constraints on $\mathrm{CO}_{2}$ emissions, by at least $64 \mathrm{GWe}$ by 2030 and by roughly 300 GWe by 2050 . These are formidable targets, requiring build-rates in excess of 10 new plants per year on a sustained basis.

Achieving a build rate of 10 plants per year, which on a sustained basis equates to about 50 plants under construction at any point in time, will require substantial investment in workforce training and new or refurbished manufacturing capability. Most of the nuclear manufacturing infrastructure that existed in the U.S. in the 1970s (heavy steel forging capacity, qualified N-stamp component suppliers, etc.) has been shuttered or diverted to other uses. The nuclear-qualified construction crews that could be mustered today are a small fraction of what will be necessary. Skilled trades in welding, piping inspection, radiation protection, nuclear quality assurance, and many other fields are barely enough to support the current fleet. The Nuclear Regulatory Commission (NRC) will therefore be challenged in reviewing and approving construction projects at the pace associated with this build rate. Financial institutions are not prepared for the magnitude of the investment that will be required. Additional limitations on such expansion will be imposed by state and local authorities over cooling water access, environmental permitting, transmission access, and other matters.

Reestablishing the infrastructure and workforce needed to support a large nuclear expansion will require substantial investment, one that is not likely to occur unless the U.S. government (both the Administration and Congress) demonstrates a commitment to the continued operation and future construction of LWRs - a commitment that must carry over from Administration to Administration. Simply 
put, companies, workers, and educational institutions are looking for a stable and supportive government policy before making large investments in people and infrastructure. ${ }^{\mathrm{h}}$ Congressional funding of the proposed LWR R\&D program will demonstrate the type of policy support needed for firms to begin making truly large-scale investments in nuclear energy infrastructure and manpower.

The elements of this plan that relate to current plants will also help reduce the demands on the U.S. nuclear plant construction infrastructure. An initiative to extend the life of the current fleet beyond the currently planned 60-year life, based on 20 -year license renewals, would reduce the required build rate for new plants by 30 to $40 \%$ during the peak construction demand period between 2030 and 2050 when the current fleet is scheduled to retire. However, the scientific and technical case to justify such an additional life extension period does not exist today. Extensive R\&D is needed on digital instrumentation and control (I\&C) applications, materials degradation, high burnup LWR fuel, etc. NRC has challenged industry to prepare for this scenario and has indicated to industry that DOE would be willing to help support the necessary research.

The list of challenges to the Administration's recommendation of an "expansion of nuclear energy in the United States as a major component of national energy policy" is formidable, and beyond the capabilities of the private sector to address fully. Market forces will eventually facilitate growth in U.S. energy infrastructure, but not fast enough to avert an energy crisis, should the Federal government continue to play the role of bystander.

To address this need for a more proactive and integrated effort by industry and government, the nuclear utility industry and

${ }^{\text {h }}$ INEEL/EXT-04-02384, U.S. Job Creation Due to Nuclear Power Resurgence in The United States Volume 1, Nov. 2004.
INL have prepared this coordinated nuclear $\mathrm{R} \& \mathrm{D}$ action plan aimed at two "stretch goals:" (1) life extension of the current fleet beyond 60 years (e.g., what would it take to extend all lives to $\sim 80$ years?); and

(2) strong, sustained expansion of ALWRs throughout this century (e.g., what would it take to proceed uninterrupted from first new plant deployments in $\sim 2015$ to sustained build-rates approaching 10+/year?).

For perspective, it is important to note that the case for government action would be even more compelling if other energy supply sectors don't achieve their maximum potential as contributors to climate change mitigation and energy security challenges. The analysis that establishes the stretch goals for the nuclear industry also assumes success in other sectors, i.e., that:

- Renewable energy will meet its goals (articulated by various state and regional renewable portfolio standards);

- Advanced coal with $\mathrm{CO}_{2}$ capture and sequestration $(\mathrm{CC} \& \mathrm{~S})$ will be successful;

- Major advances in energy efficiency will materialize.

If for any reason (e.g., technology risk, cost, or public acceptance of vast underground storage of $\mathrm{CO}_{2}$ ), these other contributors to reduced $\mathrm{CO}_{2}$ emissions fail to materialize, nuclear energy would likely be challenged to

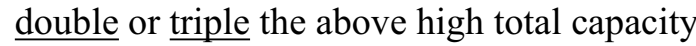
and accompanying high growth rates. This possibility reinforces the caution that it would be irresponsible to assume that all challenges to the expansion of nuclear energy can be delegated to industry.

Industry is acutely sensitive to the concern that DOE should not be tasked to do what industry can and should do to advance LWR technology. This plan assumes that industry will cost share LWR R\&D programs at an average of $50 \%$. It also assumes adoption of a rigorous process to focus DOE resources on the higher risk and longer term elements of the R\&D plan. In general, those actions that DOE would take under this plan will 
focus on critical barriers to the expansion of nuclear energy that industry and DOE agree require Federal assistance. Further, such DOE assistance will be limited to efforts that address these barriers only to the point that industry can assume the responsibility on its own. For completeness, this plan contains selected R\&D objectives that industry is currently responsible for, but that are of sufficient strategic importance to include here.

Some of the reasons that Federal engagement is necessary include:

1. The science and engineering basis to meet the above stretch goals (high new plant build rates and life extension to 80 years) is inadequate. Example: sustaining high performance of reactor plant materials (see Objective 1)

2. The NRC licensing basis for implementing certain critical technologies is inadequate, requiring DOE-assisted demonstration; similar to the rationale for DOE support to NP2010. Example: Digital I\&C (see Objective 2)

3. Facilities and resources within industry to conduct the necessary research are inadequate; unique national lab facilities are required. Example: Nuclear fuel research (see Objective 3)

4. The infrastructure required to meet the above stretch goals is inadequate, requiring Federal engagement. Examples: Workforce and physical infrastructure shortfalls (See Objectives 4 and 5)
5. Federal engagement in energy-sector wide obstacles to both nuclear and nonnuclear generation is critical to a major expansion of nuclear energy. Example: Alternate cooling technologies and high voltage transmission infrastructure (see Objective 6)

International collaboration is essential to the success of these LWR initiatives. In many cases, other nations are looking to the U.S. for leadership. In other cases, especially regarding how to build new LWRs on time, on schedule, and with exceptional quality, the U.S. has much to learn from other nations, especially Japan and France. Importantly, enhanced nuclear safety and nuclear nonproliferation result from U.S. collaboration with other nations in nuclear R\&D. America's fundamental national interest in homeland security and energy security are served when the U.S. is a major international player in the peaceful use of nuclear energy, including its RD\&D support on a collaborative basis.

Finally, this Plan presents critical nuclear energy $R \& D$ needs in an integrated technology-based strategy. Most R\&D objectives (presented later) benefit both currently operating plants and future ALWRs. Before introducing those objectives, the strategy and goals for both existing and ALWRs are presented sequentially. 


\section{The Strategy for Existing LWRs}

An examination of the options for increasing nuclear energy's share of production leads to the conclusion that achieving the stated vision cannot be based solely on building new plants. The existing fleet must also be sustained for a longer period of commercial operation to lower the required new build rate. This gives rise to two goals for existing LWRs: (1) successfully achieve planned life extensions to 60 years and further extend the NRC licenses of existing LWRs to 80 years, and (2) maintain plant performance to ensure the high capacity factor and superior safety and economic performance of LWRs throughout their 80-year lifetime.

The existing fleet of 104 nuclear power plants in the U.S. ranges from 500-1400 MWe and are located on 66 sites in 31 states. The plants now range from 12 to 38 years old. The initial license expirations would have ranged from 2009 through 2035 ,

\section{Light Water Reactor Goals}

Goal 1: Successfully achieve planned life extensions to 60 years and further extend the NRC licenses of existing LWRs to 80 years.

Goal 2: Maintain plant performance to ensure the high capacity factor and superior safety and economic performance of LWRs throughout their 80-year lifetime. without a major effort by industry and NRC to extend these licenses. As of September 2007, 48 units have been granted 20-year license renewals by the Nuclear Regulatory Commission (NRC), 14 more are in process, and over 30 units have stated their intent to file for license renewal. Given this success, it is assumed that all of the current plants will be licensed to 60 years. This will extend the expiration dates from 2029 through 2055. However, to extend the first plant retirements past mid-century will require another round of license extensions to 80 years. The first of these renewals are expected to be filed in the 2015-2020 timeframe, due to the lead times required for this important business decision. The R\&D that is needed to support these applications needs to start now, based on past experience, in order to be ready in time.

Licenses alone do not assure high levels of nuclear generation - the plants must have high availability and productivity and low production costs as well as continue their excellent safety records. All of these attributes are reflected in the fleet's capacity factor: a unit will be dispatched to produce power only if the plant is not in a scheduled or unscheduled outage, and only if its production cost is the lowest available on the market. The existing fleet now operates with an average $90 \%$ capacity factor, far superior to its $56 \%$ capacity factor 25 years ago, primarily due to improvements in plant operations, training, equipment maintenance 
and reliability, production costs, and plant capacity. These improvements came from both effective management and advances in technology. To successfully operate the fleet to 60 or even 80 years will require more research and additional technology improvements to both meet the unforeseen challenges of advancing nuclear plant age and to optimize performance.

Some of the significant challenges that will need to be addressed to achieve these LWR goals include:

- A significant fraction of the workforce in current plants is nearing retirement.

- The cost of uranium fuel is rising, driven partly in expectation of new construction as well as the costs of competing energy supplies - such as coal-rising in anticipation of the external cost of carbon management.

- The cost of maintaining obsolete analog control systems is rising rapidly, while the benefits of upgrading our nuclear plants with state-of-the-art digital technology are delayed by regulatory hurdles.
- The lack of realistic safety analyses of design basis accidents in NRC regulations is preventing adoption of a performance-based approach to managing safety.

- Environmental degradation (the combined effects of long-term irradiation, temperature and water chemistry on pressure vessel materials) is emerging as a potential issue in life extension beyond 60 years.

- Low-level waste disposal capacity will be extremely limited due to failure of most regional compacts, necessitating new siting options and further development of enhanced waste minimization technologies.

- Allowable worker exposure may be limited to 2 rem annually (down from 5 rem), necessitating innovative strategies for avoiding unmanageable workforce impacts. 


\section{The Strategy for Advanced LWRs}

For nuclear energy to grow in the first half of this century ALWRs must be built and operated in large numbers - about 60 new units by 2030 - to meet the target stated earlier. This objective prompts four additional goals: (3) successfully license, construct, and operate the first mover ALWRs through their first decade, (4) remove the barriers to deployment of many new ALWRs, (5) address lessons learned from the first ALWRs by developing new technologies to improve performance, and (6) enable new missions and markets for ALWRs, including ones beyond electricity production.

\section{Advanced Light Water Reactor Goals}

Goal 3: Successfully license, construct and operate the first mover ALWRs through their first decade.

Goal 4: Remove the barriers to deployment of many new ALWRs.

Goal 5: Address lessons learned from the first ALWRs by developing new technologies to improve performance.

Goal 6: Enable new missions and markets for ALWRs beyond electricity production.

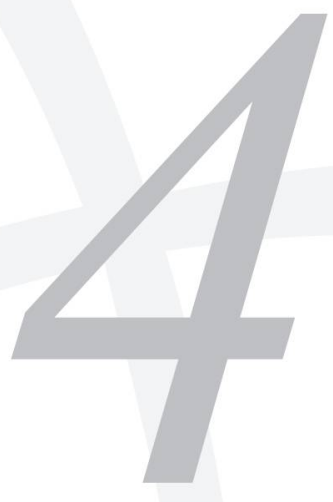

With the advent of the NP-2010 program, plans for constructing new nuclear plants are moving forward in the U.S., with 15 companies in the process of preparing license applications for about 30 new reactors. These applications will start arriving at the NRC this year, and will take about three years to review. Long-lead components are being ordered and will be staged on site; site preparation work can begin before the NRC issues a license. In addition, safety-related construction can begin under certain conditions. Based on current estimates, new nuclear plants will be coming on line by about 2015 , with an initial group of first movers in operation between 2015 and 2020. Based on past experience, it will be crucial to anticipate and effectively address early problems that may arise when bringing this new generation of ALWRs online.

Even if the first movers are successfully brought online, there will be nontechnical barriers to large-scale deployment. These barriers must therefore be anticipated and addressed now, so that follow-on plants can be constructed without interruption. All new units, for example, require fabrication of heavy section pressure vessels that are currently available from only a single factory worldwide. Also, unless the infrastructure can be expanded in time, a build rate of several units per year will strain the skilled crafts workforce and the suppliers of nuclear-grade components and 
equipment. A build rate above five per year will strain investment capital markets, professional workforce, and even the NRC's ability to review applications and regulate the new plants. All of these nontechnical issues need to be addressed. In many cases, advanced technologies will be part of the solution.

As with the existing LWRs, the long-term success of ALWRs will depend on the ability to assure their continued high performance and capacity for many decades, which coincides with Goal 2 through crosscutting developments in materials, components, workforce, and management. These factors must be defined and explored jointly for LWRs and ALWRs.

Alternative cooling technologies for both current and new plants throughout the U.S. are required to address cooling water supply issues of electricity generation. This need is driven by both increased power demand in arid regions and by environmental regulation requirements for increased reliance on cooling towers over direct cycle cooling, which in turn will drive the need to find new cooling tower technology that avoids both the high costs of passive cooling towers as well as the high parasitic power loads of forced air systems.

Finally, a long-term opportunity exists for ALWRs to move into broader energy missions and markets beyond electricity generation. These include desalination of seawater for the production of potable water and economically-competitive mid-sized units for markets that cannot be served with barge access during construction for large component placement, as is available at coastal sites or on navigable rivers.

Some of the significant challenges that will need to be addressed to achieve ALWR goals include:

- Construction costs and schedules must be reduced.

- The development of the workforce for new nuclear plants will be in competition with the large projected demands of other energy generation projects in the coming decades.

- The economics of increasing the new nuclear build rate is not well understood in terms of the constraints of infrastructure development, capital markets, and commodities.

- Greater regulatory acceptance of riskinformed safety principles will be needed to allow more realistic reactor safety analyses results.

- Clean water for the cooling of new plants will become increasingly scarce.

- High voltage transmission lines must be installed to connect new generating plants with existing grid infrastructure.

- The adoption of modern, digital I\&C is crucial to the performance and longevity of the new plants. 


\section{Research and Development Scope and Objectives}

To advance toward these six goals, 10 R\&D objectives have been identified. Many of these objectives support more than one goal - the connections between the R\&D objectives and goals are presented in the Table on page 16.

The first six R\&D objectives, as listed and described below, are considered the highest priority. These six objectives should be addressed first, as DOE and industry develop their detailed implementation plans based on this strategy. Note that objectives 1-5 are either unique to nuclear energy or face unique challenges in a nuclear energy context that greatly exceed the comparable challenges in other energy sectors. However, objective \#6 stands out as not being unique to nuclear energy, and thus requires clarification:

"Address electricity infrastructure-wide problems that are NOT unique to nuclear energy but nevertheless pose unacceptable risks to current plant operations and new plant siting."

Industry considers the two sub-objectives identified here (alternative cooling technologies and high voltage transmission infrastructure) to have high importance, but does not believe that the nuclear sector of the industry or the DOE Office of Nuclear Energy should take the lead on addressing them. Rather, nuclear energy should articulate their importance to those organizations primarily responsible for these acute national infrastructure problems, and provide supporting input to their resolution, in balance with the other energy supply sectors also challenged by them.

\section{Sustain high performance of reactor plant materials}

a. Extend component life and improve lifetime prediction

Although great advances have been made in component life since the dawn of nuclear power, new issues, such as environmental degradation of structural and vessel materials, continue to emerge and challenge the extension of plant life beyond 60 years. This research area would develop the scientific basis by generating and understanding relevant laboratory and field data on corrosion and other materials degradation. It would address issues in irreplaceable civil structures such as containment tendons and concrete at elevated service temperatures, as well as cabling and underground piping in plants past 60 years. It would 'mine' the data from structures and vessels currently being decommissioned - both power and test reactors worldwide - a task that has to date proven difficult. It would also investigate and understand the many potential environmental precursors of degradation. This understanding would support mechanism-based component life 
predictions for critical structures, systems, and components and reduce the uncertainty in component life predictions. It would also provide drivers and insights for developing components with longer life, or for possibly pursuing life extension methods such as pressure vessel annealing.

b. Improve in-service equipment inspection, diagnostic, maintenance, and repair techniques

As an example of the complexity of modern plants, there are over 750 bolts inside the vessel of an ALWR, which drive the in-vessel inspection requirements during outages. This research area would develop improved repair, replacement, and mitigation techniques for many components, including 'on-line' techniques that do not require plant shutdown, as well as strategies for addressing equipment obsolescence. It would analyze and integrate results from 'sentinel' materials samples in support of predictive capability. It would also develop traditional and risk-based inspection capabilities based on emerging measurement and information management technologies that dramatically improve the prediction and management of materials and equipment degradation, significantly reducing plant operational limits imposed by current uncertainties in flaw detection, especially in stainless steels. There is a close correlation between the enhanced In-service NonDestructive Examination (NDE) techniques developed for this R\&D objective and the Pre-service NDE techniques developed for Objective 7 below. Further, the potential for reducing the annual worker exposure to 2 rem (from $5 \mathrm{rem}$ ), drives the need for automation and reduced human intervention. This area would require the development of advanced robotics with high potential for alleviating the impacts on current and future plants.

c. Develop innovative materials

Research into materials is nearly half of EPRI's research budget, yet much more needs to be done. The DOE Office of Science has significant capabilities that can be brought to bear on understanding fundamental materials degradation mechanisms, which in turn will enable innovations in new materials that are even more resistant to cracking, corrosion, and other mechanisms. Key objectives include (1) understanding why Inconel and other high temperature alloys crack, (2) innovations in advanced alloys and ceramics, (3) nanotechnology-based materials, and (4) integrated materials performance and coolant chemistry control.

2. Transition to state-of-the-art digital I\&C

Digital systems are proven technology used by most industries throughout the world.

They enhance safety, reliability, and functionality, but have proven difficult to license in U.S. nuclear plants. This research area would facilitate the transition to state-of-the-art digital I\&C technology by applying experience in other industries and in nuclear applications overseas to the U.S. regulatory review process, and by establishing pilot programs as necessary to support the NRC's ability to license modern digital I\&C systems - for new systems as well as upgrades/replacements to existing systems. This effort is not intended to develop new technologies, since digital I\&C technology development is proceeding at a rapid pace through other industry and government supported research. Rather it is intended to bring the additional contributions that DOE can make to an unsatisfactory regulatory basis for upgrading obsolete analog systems with modern digital systems and keeping pace with these systems as they continue to improve. New plant I\&C systems are proceeding with suboptimal regulatory standards. Even greater challenges face current plant I\&C upgrade initiatives, necessitating one or more pilot demonstration programs to resolve these issues. 
3. Advances in nuclear fuel

a. Enhance fuel reliability and performance

In 2006, the nuclear industry approved an industry-wide initiative to "Take high impact actions to significantly improve fuel cladding performance in support of Industry 2010 goals." Known as the "Zero [defect] by 2010" initiative, this INPOled initiative is requiring extensive industry R\&D into the root cause of fuel defects, by EPRI and the nuclear fuel vendors. Hot cell examinations of fuel defects are critical to understanding these root causes, which include grid-to-rod fretting, pellet-clad interaction, corrosion and crud effects, etc. The unique facilities of the national labs are, in turn, critical to the success of the surveillance and inspection aspects of this program. In addition, longer term solutions need to be studied, including innovations in fuel/clad systems based on carbide or nitride fuel, and annular, high density fuels. Again, national laboratory facilities are key to progress.

b. Develop high-burnup (HBU) fuel

In the 1980s, a prior 'HBU fuel program' sponsored by DOE and industry successfully increased the performance of fuel to 50,000 MWD/MT (up from 30,000). Progress beyond that increase has been gradual, yet fuel costs have risen five-fold in recent years and a new core load now costs over $\$ 100 \mathrm{M}$. Working closely with fuel vendors, this research area would develop highly reliable HBU, high-performance fuels, aimed at a goal of 85,000 MWD/MT. The HBU fuel program is expected to take about 10 years, and involves test and qualification of innovative fuels with uranium enrichment above $5 \%$. This work must be integrated with current industry efforts to improve the reliability of the current generation of LWR fuel. The upgrading of the test and examination infrastructure to support this research area is addressed in area 1A above. Finally, significant work is required to support the NRC qualification acceptance of storage and transportation casks for HBU fuel.

4. Implement broad-spectrum workforce development

Workforce shortages that impact the nuclear industry are emerging rapidly and range over the complete spectrum from skilled crafts and technicians through professionals with advanced degrees in mechanical, civil, electrical, chemical, and nuclear engineering. This area would address the broad spectrum with proactive initiatives and research to (1) develop the manufacturing, skilled worker, and workforce infrastructure supporting expanded LWR deployment and operation, including an effective regulatory workforce, (2) establish the educational partnerships and foundations necessary to leverage the development, and (3) facilitate the transfer of plant operating knowledge to a licensee workforce increasingly comprised of less experienced employees. The Department of Labor already has extensive programs, working with universities, colleges, and community colleges, to expand skilled worker training programs. DOE would work with DOL, INPO, NEI, and state/regional consortia, to meet nuclear industry specific training needs.

5. Implement broad-spectrum infrastructure improvements and design for sustainability

The advancing age and retirement of nuclear-capable manufacturing and testing infrastructure is a critical issue for the expansion and continued performance of the nuclear fleet. There are three major objectives in this area. First, the development of U.S. manufacturing infrastructure beyond the current capability, which is limited to a build rate of about two reactors per year. This needs to reach a level between 5 and 10 reactors per year in the next decade. This can be done by proactively addressing supply bottlenecks in nuclear-grade ultra-heavy (pressure vessel) and heavy forgings, specialty 
components such as nuclear grade pumps and valves, subcomponents, and materials. Second, means should be found to address the demand side by reducing the raw materials and alloys needed to build new plants, thereby improving the sustainability of expanded deployment of nuclear plants. Third, the rebuilding of irradiation test and examination infrastructure at the national laboratories is needed to execute much of the fuels and materials advances called for above.

These proactive developments must be guided with a better understanding of the economics of an expanded nuclear build rate, especially with regard to the inelasticity of infrastructure and workforce development, capital markets, and commodity usage. The constraints to nuclear expansion must be understood within the broader outlook for energy markets and policies. Of course, this is not an issue unique to nuclear power-all major energy sources that could significantly contribute to mitigation of climate change face such constraints. The nuclear industry will be relying on overseas suppliers for much of these infrastructure needs in the near term. However, over-reliance on overseas suppliers could impact the timing and reliability of the supply chain, requiring a closer look at which aspects the U.S. must supply.

6. Address electricity infrastructure-wide problems that are NOT unique to nuclear energy but nevertheless pose unacceptable risks to current plant operations and new plant siting

a. Develop alternative cooling technologies

Most nuclear plants built in the future will be unable to access enough clean water to use the current technology of natural draft evaporative cooling towers. Further, the costs of large concrete structures, such as cooling towers, is rapidly escalating, and new power plants may be forced to use reclaimed water, which introduces corrosion and fouling issues. Conventional 'dry cooling' greatly reduces the water required but incurs large (over 15\%) parasitic power losses. Alternative cooling technology is needed, but little is on the horizon with promise today. A major objective of this research area is the development of needed alternative cooling methods. Given the mandate of 316B legislation, DOE needs to strike a balance between the competing environmental goals of species protection and water conservation.

b. Expand high-voltage transmission infrastructure

Improving transmission and distribution technologies and resolving siting and right-of-way issues are critical to the siting of new generating plants of all types.

7. Advanced fabrication, construction and inspection methods

The first mover ALWRs will likely take five or six years to construct, and are still very dependent upon field construction and inspection. This research area would broadly address the need to reduce construction project cost and duration through revolutionary equipment designs, fabrication, and construction methods. These techniques hold the promise of greatly decreasing the construction schedule and relative cost, compared to existing nuclear plants, while simultaneously improving quality and minimizing the amount of site construction and inspection time needed. It would also seek new models for fabricating components and modules, drawing upon successful models in the aircraft and shipbuilding industries.

8. Extend the application of risk management technologies and understanding of safety $\underline{\text { margins }}$

This research area would expand the use of probabilistic risk assessment, risk insights, configuration risk management, and other risk-based tools to improve safety; optimize programs, processes, and regulations; and optimize designs for future plants. It would also develop an improved understanding of safety margins through state-of-the-art 
simulation and modeling, reactor safety and design analysis, and risk based technology. For example, redefining the break size for licensing purposes from the current largebreak loss-of-coolant-accident basis to a more risk-informed basis may become an essential prerequisite to life extension beyond 60 years. There is a need to develop pinby-pin safety margin analysis, which is estimated to take 5 years to achieve. Further, the recent Kashiwazaki-Kariwa plant earthquake in Japan highlights the need to address safety margins in seismic design. For plants going to 80 years, this research area would address how to incorporate the potential changes in failure rates of equipment into risk calculations. Methodology needs to be developed for representing the impact of aging on failure statistics. Finally, safety analyses and emergency response guidelines will benefit from research being performed by the DOE Office of Science into more accurate epidemiological data regarding the health effects of low doses of radiation.

9. Improve operational performance

The need to keep nuclear power's cost attractive as a base load supply drives the need to improve operational performance. This research area would support a wide variety of improvements, including (1) improved equipment reliability; (2) plant power uprates that are integrated with their impacts on plant life extension; (3) technologies for plant security, with a focus on reducing the manpower needs of security; (4) advanced power electronics; (5) spent fuel management; (6) Low level waste minimization, and (7) riskinformed technologies and operations developed in conjunction with probabilistic risk assessment.

10. Expand LWR technology into new missions and markets

a. Develop LWRs for application in regional markets

To enhance its widespread use, nuclear energy should be developed to meet market needs in regions of the U.S. that cannot support the deployment of the very large plants currently undergoing licensing review, with their requirements for barge access and transport of ultra-heavy components. As an illustration, the heaviest equipment transportable on rail is 800 tons (about double the weight of a modern ALWR vessel), but is limited to a height of 16 feet $^{\mathrm{i}}$ above the rail surface-well below the 20 foot diameter of a modern vessel. This research area would assess the economic and technical feasibility of developing optimum-size plants to meet this need, balancing economies of scale with the above constraints. This area may also consider markets that need or could use ALWRs of sizes even larger than those being licensed today, as dictated by regional demand.

b. Develop desalination and process heat technologies

In the mid-term, growing water shortages portend the need to develop the technology and licensing basis for coupling LWR and desalination technologies to produce potable water. In the long term, this research area should also address the connection of low-temperature nuclear heat from LWRs to low or medium temperature production of transportation fuels such as biofuels, oils, and recovery or thermally-assisted electrolysis for hydrogen production, thereby opening new markets and reducing cooling needs.

The connections between the 10 research areas and six program goals are shown in the table on the next page. R\&D that is key to advancing a goal is indicated in green. R\&D that would diffuse into the technologies, components, or systems that advance toward a goal is indicated in light blue.

\footnotetext{
${ }^{i}$ Representative western U.S. loading gauge, http://en.wikipedia.org/wiki/Loading_gauge\#North_America, and the largest Schnabel car in North American service, http://en.wikipedia.org/wiki/Schnabel_car
} 


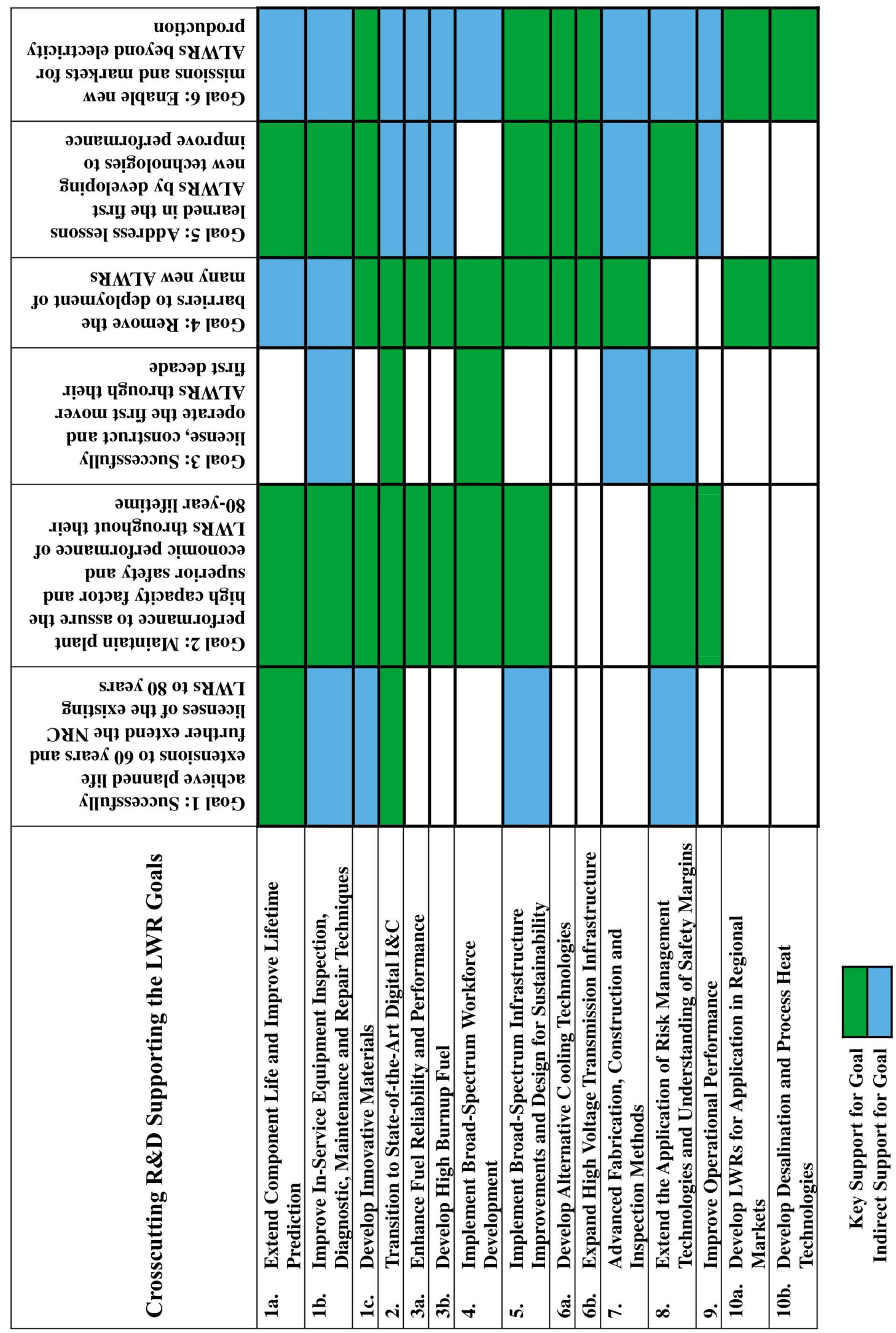




\section{The Path Forward}

\section{Collaborative Program Planning and Joint Funding}

The proposed areas of research call for a needed expansion in the level of effort currently undertaken by industry $R \& D$ programs and are beyond the scope of current DOE nuclear energy R\&D programs.

- For new ALWRs, the work identified in this plan goes beyond the current plans for the cost-shared NP-2010 program. It could be addressed by either an expansion of NP-2010 or by a new program.

- For current LWRs, Section 952 of the Energy Policy Act of 2005 authorized a Nuclear Energy Systems Support Program (NESSP) that directed DOE "...to support research and development activities addressing reliability, availability, productivity, component aging, safety, and security of existing nuclear power plants." To date, no funding has been requested or authorized for this program. NESSP is an appropriate vehicle for managing the type of work identified here for current plants.

Regarding research efforts to meet pressing national needs, such as technologies to mitigate global climate change, the National Academy of Sciences has concluded that:

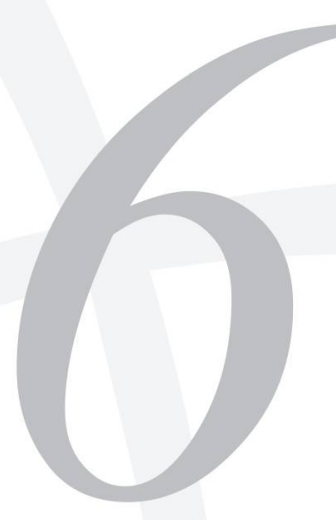

“...the most pressing technological problems of this nation cannot be solved by one company, one university, or one federal agency...these are challenges that require multiple sectors to come together to forge a solution. ${ }^{, j}$

The research agenda proposed by this strategy is needed for nuclear energy to expand dramatically, is clearly in the national interest, and will require substantial participation by industry, academia, and Federal government. Experience shows that $R \& D$ programs of common interest should be conducted as collaborative, cost-shared activities whenever possible. In doing so, greater assurance is provided that common visions, goals, and objectives will be achieved and that duplication and gaps in technology development will be eliminated. Another benefit of cost-shared activities is the leveraging of limited $R \& D$ resources.

It is expected that industry and DOE will cost-share the work needed to execute this plan. It is suggested that DOE seek funding for this proposed strategic R\&D scope as soon as possible.

This proposed work has much in common with other R\&D energy technology programs currently being funded by DOE.

\footnotetext{
${ }^{j}$ NAS Government-University-Industry Research Roundtable, http://www7.nationalacademies.org/guirr/
} 
These parallels are described in the Appendix.

Previous collaborative research between DOE and industry has been implemented under two broad categories:

1. Collaborative and cost-shared activities: Work in this category is performed jointly by DOE and industry on a partnership basis. These activities involve, to a certain degree, joint management and/or joint funding.

2. Coordinated but independent activities: Work in this category pertains to related activities performed separately and funded individually by DOE and industry, either because the work may need to remain independent, or because the work may not be appropriate for government funding. Although these efforts are managed individually, using standard, approved processes for R\&D management, they may be coordinated through joint planning (to ensure no overlaps and gaps in respective programs), joint communications on plans, and where appropriate, joint program review as work progresses.

The majority of the R\&D activities proposed in this plan are expected to fall under the first category. Although there will be a number of R\&D activities related to this plan's goals and objectives that will be conducted under the latter category, this work will be coordinated by DOE and industry to minimize duplication of effort.

It is recognized that this plan represents a roadmap for joint industry-government cooperation in LWR R\&D, along with the best scope definition and prioritization that industry can provide - prior to more detailed engagement with DOE. A more detailed version of this plan (or a separate implementation plan) would be required to expand the level of detail in each of the R\&D objective areas and to identify the specific tasks to be funded using the collaborative approaches above. Detailed cost estimates and appropriate allocations of funding responsibility for industry and government on an R\&D objective or other programmatic basis would be developed, along with a schedule to carry out the R\&D. On average, an overall cost share by industry of $50 \%$ would be achieved. Some longer range or higher risk tasks would likely be funded on an $80 \%$-DOE / $20 \%$ industry basis, while some shorter term tasks would likely be funded on an $80 \%$-industry / $20 \%$-DOE basis. Given the levels of current industry investment in LWR R\&D in relation to the additional work proposed here, a rough estimate of the level of Federal funding required should start in the $\$ 30$ million to $\$ 50$ million/year range, and ramp up to approximately $\$ 100$ million per year over a limited period as these challenges are addressed.

Though the workscope set forth in this plan is intended to be conducted by DOE and industry, NRC may want some level of involvement in the research to ensure the right areas are being addressed and the resulting generic data are sufficient to show that regulations governing license renewal can be met over the extended term. The program participants would welcome such involvement and intend to share information and coordinate with the NRC as appropriate.

\section{The DOE/Industry Management Team}

A new management team is proposed to implement this joint DOE-industry strategic plan. That team will be comprised of the DOE Office of Nuclear Energy (NE) and industry participants. An executive committee will be formed consisting of the NE Deputy Director for Technology plus two or three additional members representing nuclear utility management: the Chairman of the EPRI Nuclear Power Council (NPC), the Chairman of the INL Utility Advisory Board, and a representative of the Nuclear Energy Institute (NEI) Nuclear Strategic Issues Advisory Committee (NSIAC). These executive bodies currently provide, in various ways, leadership on industry research needs and resource prioritization (including authority 
over industry cost-share), independent advisory input to government on industry priorities, and overall leadership for the nuclear industry on technical and regulatory issues. Together, these utility executives represent all U.S. nuclear power plant licensees. Their participation would ensure optimal R\&D planning and cost sharing.

The LWR R\&D Executive Committee would meet at least annually to:

- Review the status and progress of ongoing cooperative research programs

- Review potential new candidate cooperative research programs

- Agree on priorities, terms, and conditions of new cooperative research initiatives

- Provide direction on continued work, termination, or other modifications, as necessary.

Assuming the proposed R\&D programs receive the necessary Federal and industry support, there will be a number of cooperative agreements initiated between DOE and industry to focus on specific demonstration tasks or pilot projects. In these cases, the progress toward these cooperative agreements will come under the oversight of the Executive Committee.

A group of participating managers primarily from the DOE Office of Nuclear Power Systems (NE-30), NEI, EPRI, INL, and utility program managers will direct the R\&D activities proposed in this plan. These managers will be supported by various task forces and groups including industry vendors and contractors addressing the type of issues and R\&D activities referenced in this plan. INL has the responsibility of coordinating expertise, where needed, throughout the DOE national laboratories.

\section{Program Direction and Oversight}

DOE and industry will seek advice on program direction from key executive-level advisory resources, including:

- EPRI Nuclear Power Council (NPC)

- INL Utility Advisory Board (UAB)

- NEI Nuclear Strategic Issues Advisory Council (NSIAC) 


\section{Appendices}




\section{Appendix A Similarities with Goals of Other DOE Energy Programs}

The goals of this LWR strategy promote the advancement of LWRs in a number of different ways. However, all of them are similar or related to those of other DOE energy programs. Examples are given below:

- Within DOE's Office of Fossil Energy (FE), the Advanced Integrated Gasification Combined Cycle (IGCC) program has a goal to make "significant advances ... to increase efficiency and reduce the capital and operating and maintenance costs and to improve both the reliability and the overall system availability." Goals 2, 3 and 5 are oriented in this direction for LWRs.

- Also within DOE-FE, the Advanced Metallurgical Research effort at the Albany Research Center is, among other things, supporting research to increase component service life through the development of affordable materials and processes for fossil energy plants. Within DOE's Energy Efficiency and Renewable Energy (EE) Office, Hybrid Electric Systems Program funds research into driving down the cost and extending the lifetime of lithium-ion batteries for vehicle applications. Goal 1 is oriented in this direction for LWRs.

- Within DOE-EE, the Wind Energy Program focuses, among other things, on providing information on a range of wind energy technologies to national, state, local and regional decision-makers and potential customers in an effort to overcome the barriers to deployment of wind energy. The DOE-EE Solar Energy Program conducts similar efforts. Goal 4 is oriented in this direction for LWRs.

- Within DOE NE, the Generation IV Initiative has provided a focus for the advancement of nuclear energy systems in the long term, including new missions for reactors. Goal 6 is oriented in this direction for LWRs, which are not included in Generation IV R\&D. 
